\title{
Quantification of circulating steroids in individual zebrafish using stacking to achieve nanomolar detection limits with capillary electrophoresis and $\mathrm{UV}$-visible absorbance detection
}

\author{
Vincent T. Nyakubaya ${ }^{1} \cdot$ Brandon C. Durney $^{1} \cdot$ Marriah C. G. Ellington $^{1}$ • \\ Amber D. Kantes ${ }^{1}$ - Paige A. Reed ${ }^{1}$ - Shaylyn E. Walter ${ }^{1}$. \\ Jennifer Ripley Stueckle ${ }^{2}$ - Lisa A. Holland ${ }^{1}$
}

Received: 5 January 2015 /Revised: 7 May 2015 / Accepted: 18 May 2015 / Published online: 4 June 2015

(C) The Author(s) 2015. This article is published with open access at Springerlink.com

\begin{abstract}
Capillary electrophoresis and UV-visible absorbance detection are used with sample stacking to achieve detection limits ranging from 0.2 to $2 \mathrm{ng} / \mathrm{mL}(0.8$ to $6 \mathrm{nM})$ for steroids. Stacking is accomplished using negatively charged cyclodextrin steroid-carrier molecules at a discrete $\mathrm{pH}$ interface between the reconstituted sample and the separation electrolyte. Steroids are then separated in under 5 min using capillary electrophoresis that incorporates secondary equilibria via sodium dodecyl sulfate and cyclodextrin. The effectiveness of the method for measurements of multiple steroids in limited sample volumes is demonstrated in individual female fish with total circulating blood volumes of $5 \mu \mathrm{L}$ or less. Steroid recoveries from plasma following a sample processing method developed with commercial extraction cartridges range from 81 to $109 \%$ for $17 \alpha, 20 \beta$-dihydroxy-pregn-4-en3 -one, testosterone, 11-ketotestosterone, estrone, $17 \beta$-estradiol, and $17 \alpha$-ethinyl estradiol. When applied to reproductively active female zebrafish, changes were detected in the levels of
\end{abstract}

Published in the topical collection Capillary Electrophoresis of Biomolecules with guest editor Lisa Holland.

Electronic supplementary material The online version of this article (doi:10.1007/s00216-015-8785-0) contains supplementary material, which is available to authorized users.

Lisa A. Holland

lisa.holland@mail.wvu.edu

1 C. Eugene Bennett Department of Chemistry, West Virginia University, Morgantown, WV 26506, USA

2 Department of Biology, West Virginia University, Morgantown, WV 26506, USA circulating steroids as a result of exposure to different solvents and $17 \beta$-estradiol.

Keywords Bioanalytical methods $\cdot$ Bioassays $\cdot$ Biological samples $\cdot$ Capillary/electrophoresis $\cdot$ Endocrine disruptors

\section{Introduction}

Endocrine-disrupting chemicals mimic natural hormones and lead to impaired reproduction and adverse health outcomes [1]. Studies with zebrafish are integral to assessing the effects of endocrine-disrupting chemicals on human health because genes, development, and the hypothalamic-pituitary-gonadal axis are similar to those of humans [2]. Chemical biomarkers in the fish, such as steroid hormones and proteins, are measured to evaluate endocrine disruption [3]. Circulating steroids are effective to study both genomic and non-genomic mechanisms of action of the endocrine system, because it is well established that reproduction involves synchronized changes in steroidal hormones [4]. In female fish, changes in levels of $17 \alpha, 20 \beta$-dihydroxy-pregn-4-en-3-one, testosterone, estrone, and $17 \beta$-estradiol induce vitellogenesis or ovulation. Endocrine-disrupting chemicals impact levels of multiple circulating steroidal hormones because they are regulated through interrelated and complex biological pathways. A set of steroid hormones must be monitored in an individual to elucidate the physiological response to toxicants because pooling plasma samples disproportionally normalizes the surges in steroid levels from outliers. 
Regulated zebrafish exposure studies for endocrine disruption utilize fish that are $16 \pm 2$ weeks of age [5], even though the total blood volume at this age is $5 \mu \mathrm{L}$ or less. Measurements of multiple circulating steroids with mass spectrometry or immunoassays are challenging in individual laboratory fish because of the limited blood volume and the number of animals investigated. Steroid hormones determined in plasma with mass spectrometry are coupled to gas chromatography or liquid chromatography [6-9]. The limited steroid volatility necessitates chemical derivatization for gas chromatography methods [6, 7]. The moderate steroid ionization efficiency of liquid chromatography generates high mass detection limits, which requires the use of plasma volumes greater than $5 \mu \mathrm{L}$ [8]. Steroid analyses accomplished using immunoassays can be performed on small plasma volumes. Only a single antibody can be assayed for a single steroidal compound, and cross-reactivity towards other steroid-like compounds must be characterized. Additionally, antibodies are not commercially available for all steroids of interest, and the performance of each antibody must be validated for plasma samples to verify that antibody-antigen binding is not affected by interfering compounds in plasma for a particular species. Measurement of circulating steroids in zebrafish has been performed using immunoassays on pooled samples and is limited to determinations of estradiol [10-14], testosterone [10-14], or 11-ketotestosterone [14]. Immunoassay measurements of a single steroid in individual samples have been reported [15-17]. Estradiol, testosterone, and 11ketotestosterone were measured in individual zebrafish aged 4-6 months that yielded plasma volumes up to $10 \mu \mathrm{L}$ [18], while estradiol and testosterone were simultaneously measured in individual zebrafish older than 17 weeks $[19,20]$.

Direct detection of steroids is feasible with UV-visible absorbance detection, but detection limits achievable with capillary electrophoresis are in the micromolar range [21]. This problem is addressed by using different stacking methods to increase the amount of steroid loaded into the capillary without increasing the band broadening associated with large injection volumes $[22,23]$. Analyte bands can be compressed based on differences in mobility in zones of background electrolyte of discontinuous conductivity as in field amplified stacking. Acidic or basic functional groups of an analyte can be harnessed by creating discontinuous regions of $\mathrm{pH}$. For charged analytes, these techniques generate concentration factors up to 6000-fold [22]. Stacking neutral steroids is more difficult, but can be accomplished with carrier molecules, such as borate, sodium dodecyl micelles, or cyclodextrins, that form a steroid complex that can be stacked [21, 24-26]. A steroid detection limit of $118 \mathrm{ng} / \mathrm{mL}$ has been realized with UV-visible absorbance by creating large injection plugs of steroids solubilized in sulfated cyclodextrin carriers that migrate out of the injection zone and transfer steroids at the interface of the cholate micelles [21]. By filling the entire capillary with sample and sweeping the steroids into a smaller band prior to separation, steroid detection limits of $30 \mathrm{ng} / \mathrm{mL}$ were realized [24]. Large-volume sweeping generated a 5-ng/ $\mathrm{mL}$ detection limit for testosterone by repeating the filling and micelle sweeping five times in a single capillary [25]. Stacking enhancement of steroids can be increased by combining multiple mechanisms for stacking. The combination of both a dynamic $\mathrm{pH}$ junction with sweeping, which resulted in 30 -fold stacking enhancement for six steroids, was better than using only one mode of stacking [26]. UV-visible absorbance detection using $\mathrm{pH}$-mediated sample stacking of the anionic stacking reagent carboxymethyl- $\beta$-cyclodextrin as a carrier for multiple steroids was optimized [27] and generated detection limits ranging from 0.8 to $4 \mathrm{ng} / \mathrm{mL}[28,29]$.

In the current study, the pH-mediated stacking was combined with field amplified stacking to reduce the detection limits to 0.2 to $2 \mathrm{ng} / \mathrm{mL}$ (0.8 to $6 \mathrm{nM}$ ) for six natural and synthetic steroids. The method of processing the plasma was modified to generate recoveries ranging from 81 to $109 \%$ from $5-\mu \mathrm{L}$ plasma volumes. With these changes, the method was suitable to detect and quantify $17 \alpha, 20 \beta$-dihydroxypregn-4-en-3-one, testosterone, 11-ketotestosterone, estrone, $17 \beta$-estradiol, and $17 \alpha$-ethinyl estradiol in $5-\mu \mathrm{L}$ plasma samples. The role and effects of circulating estrogenic steroids in females are well documented in fish that produce larger plasma volumes [30, 31], but not in small model female fish. The applicability of the method was tested by measuring circulating steroids following exposure of individual female zebrafish to $17 \beta$-estradiol, which is a positive control for estrogenic activity [5]. This new analytical technology provided unprecedented information about the effects of $17 \beta$-estradiol as well as the delivery solvent.

\section{Experimental}

Sample processing Additional experimental details are provided as electronic supplementary material. Processing and sample analysis are briefly summarized here. Plasma samples were diluted with deionized water to bring each sample up to a volume of $25 \mu \mathrm{L}$, mixed, and then extracted in $75 \mu \mathrm{L}$ of ethyl acetate. The extraction was repeated three times, and each ethyl acetate extraction combined to a total volume of $225 \mu \mathrm{L}$. The pooled ethyl acetate was evaporated to dryness at ambient temperature using a SpeedVac concentrator with a refrigerated vapor trap (Thermo Scientific, Waltham, MA, USA) in approximately $15 \mathrm{~min}$. Once dried, the samples were reconstituted in a $200-\mu \mathrm{L}$ solution of $1: 3$ water $-1 \%$ formic acid in acetonitrile. This $200-\mu \mathrm{L}$ solution was then applied to a Hybrid SPE phospholipid cartridge (Sigma-Aldrich, St. Louis, MO, USA), which was then rinsed with an additional $200 \mu \mathrm{L}$ solution of $1: 3$ water $-1 \%$ formic acid in acetonitrile. A total volume of $400 \mu \mathrm{L}$ of $1: 3$ water- $1 \%$ formic acid in 
acetonitrile was collected and evaporated to dryness at ambient temperature using a SpeedVac concentrator in approximately $90 \mathrm{~min}$. The dried fraction was reconstituted in $1000 \mu \mathrm{L} 90 \% 5 \mathrm{mM} 3$-( $N$-morpholino)-propanesulfonic acid and $10 \%$ methanol and applied to a Discovery reversed-phase cartridge (Sigma-Aldrich) that had been conditioned with $5 \mathrm{~mL}$ of methanol followed by $5 \mathrm{~mL}$ of deionized water. The reversed-phase cartridge was then washed with $2 \mathrm{~mL}$ of deionized water. After this wash, the steroids were eluted with a $0.5 \mathrm{~mL}$ volume of methanol, which was collected and then evaporated to dryness at ambient temperature using a SpeedVac concentrator in approximately $60 \mathrm{~min}$. The dried sample was reconstituted in $30 \mu \mathrm{L}$ of the stacking solution.

Steroid separation The neutral steroidal compounds are separated based on secondary equilibria with sodium dodecyl micelles and hydroxypropyl $\beta$-cyclodextrin. The separation is accomplished with reversed polarity in under 5 min using an acidic background electrolyte to suppress electroosmotic flow. The charged steroid-cyclodextrin complex is injected electrokinetically into the separation capillary but becomes neutral when it encounters the acidic $\mathrm{pH}$ of the separation buffer in the capillary. During injection, the migration velocity of the neutral complex drops to zero, stacking analyte within the capillary prior to separation. Capillary electrophoresis separations were accomplished at $25{ }^{\circ} \mathrm{C}$ using a $25 \mu \mathrm{m}$ id, $360 \mu \mathrm{m}$ od, 30-cm-long fused silica capillary (Polymicro Technologies, LLC, Phoenix, AZ, USA) with an effective length of $10.2 \mathrm{~cm}$ and a background electrolyte comprised of $30 \mathrm{mM}$ sodium dodecyl sulfate, $13 \mathrm{mM}$ hydroxypropyl- $\beta-\mathrm{CD}$, and $200 \mathrm{mM}$ phosphate buffered at $\mathrm{pH}$ 2.5. Separations were performed at $16 \mathrm{kV}$ with reversed polarity. The smaller inner diameter capillary is used to maintain currents at or below $35 \mu \mathrm{A}$. The sample was introduced using a $10-\mathrm{kV}, 60-\mathrm{s} \mathrm{pH}-$ mediated electrokinetic stacking accomplished by reconstituting standards or samples in $30 \mu \mathrm{L}$ of stacking electrolyte comprised of $1 \mathrm{mM}$ carboxymethyl- $\beta$-cyclodextrin, $5 \%$ methanol, and $5 \mathrm{mM} \mathrm{CAPS}$ buffered at $\mathrm{pH} 10$.

\section{Safety considerations}

Steroids and endocrine disruptors require the use of personnel protective equipment. Consult the MSDS for each compound prior to use.

\section{Results and discussion}

Improved stacking The $\mathrm{pH}$-mediated carboxymethyl- $\beta$ cyclodextrin stacking was most effective when the negatively charged cyclodextrins were driven from the sample vial into the separation capillary at the highest velocity achievable.
This ensured that the maximum number of carboxymethyl $\beta$-cyclodextrin carriers accumulated at the interface of the basic stacking buffer and acidic separation buffer. A lowconductivity stacking solution induced a high velocity of the carboxymethyl- $\beta$-cyclodextrin ions, because these ions experienced a high electric field when a voltage was applied [32]. The solution conductivity, $\sigma$, is a function of the Faraday constant, $F$, the concentration, $C$, the electrophoretic mobility, $\mu$, and the charge, $z$, as defined by Eq. 1 [33].

$\sigma=F \Sigma C_{\mathrm{i}} \mu_{\mathrm{i}} z_{\mathrm{i}}$

Previously, steroid analysis was reported using a stacking solution of $50 \mathrm{mM}$ CAPS buffered to $\mathrm{pH} 10[28,29]$. A decrease in the CAPS concentration in the stacking solution from 50 to $5 \mathrm{mM}$ reduced the calculated conductivity of the sample matrix by a factor of eight. The steroidal compounds with high affinity for carboxymethyl- $\beta$ cyclodextrin should approach this concentration factor. As shown in Fig. 1, a stacking solution comprised of $1 \mathrm{mM}$ carboxymethyl- $\beta$-cyclodextrin and $5 \mathrm{mM}$ CAPS produced peak areas that were four to six times larger than those obtained with a stacking solution comprised of $1 \mathrm{mM}$ carboxymethyl- $\beta$-cyclodextrin and $50 \mathrm{mM}$ CAPS (see Electronic Supplementary Material (ESM) Table S1). The limits of detection determined with a 5-mM CAPS stacking buffer using standards ranging from 20 to $100 \mathrm{nM}(n=10)$ improved as follows: $17 \alpha, 20 \beta$-dihydroxy-pregn-4-en-3-one $(3.17 \pm 0.06 \mathrm{nM})$, testosterone $(2.8 \pm 0.1 \mathrm{nM}), 11$-ketotestosterone $(6.4 \pm 0.2 \mathrm{nM})$, estrone $(2.69 \pm 0.09 \mathrm{nM}), 17 \beta$-estradiol $(0.79 \pm 0.05 \mathrm{nM})$, and $17 \alpha$-ethinyl estradiol $(0.96 \pm 0.04 \mathrm{nM})$. These detection limits, summarized in Table 1, were four to five times lower than that reported previously for $17 \alpha, 20 \beta$-dihydroxy-pregn-4-en-3-one, $17 \beta$-estradiol, and $17 \alpha$-ethinyl estradiol. CAPS concentrations less than $5 \mathrm{mM}$ were evaluated; however, the stacking was not reproducible.

Method characterization Analytical figures of merit of the improved stacking and separation method that were characterized using standards included the linear range of quantification, precision in migration time, and area for the new stacking conditions (see Table 2). The within-day and day-to-day variations in migration time precision were less than or equal to 1 and $10 \% \mathrm{RSD}$, respectively. The higher variation in migration time across days did not impact quantification as calibration curves were constructed daily and repeated after ten consecutive runs. Nevertheless, the migration time variation across day may originate from a slight change in the separation background electrolyte, which was made daily. This was because the apparent mobility of steroidal compounds is based on competitive equilibria between anionic sodium dodecyl sulfate micelles and neutral hydroxypropyl $\beta$ - 

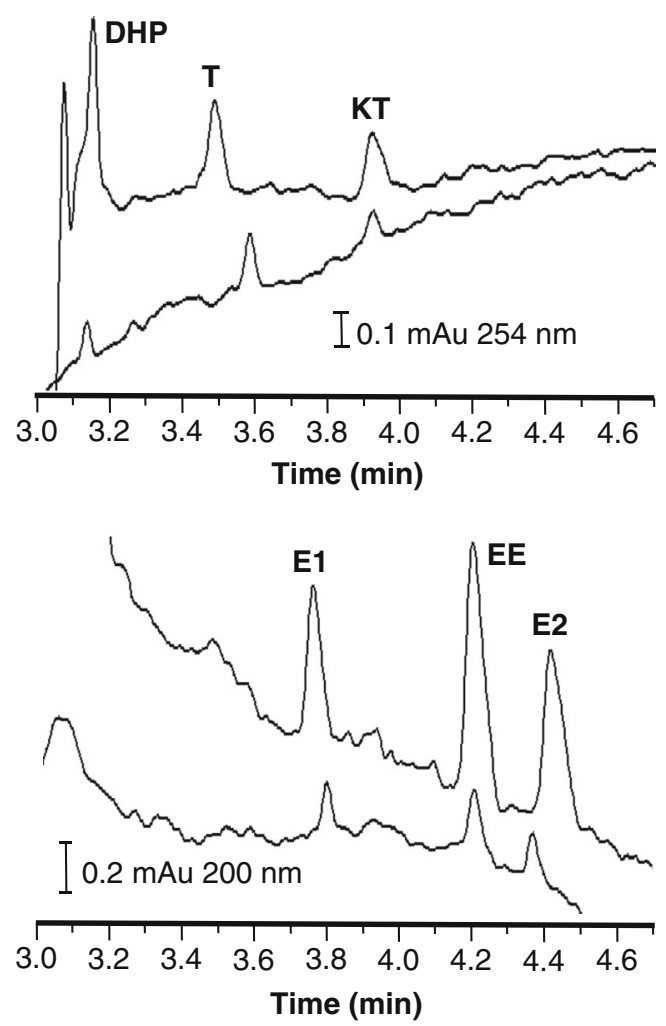

Fig. 1 Electropherograms of steroid stacking at 200 and $254 \mathrm{~nm}$ demonstrate enhancement in area ranging from $3.7 \pm 0.2$ to $5.6 \pm 0.3$ observed with change in CAPS concentration from 50 to $5 \mathrm{mM}$ CAPS. Peak labels are as follows: estrone $(E 1), 17 \alpha$-ethinyl estradiol $(E E), 17 \beta$ estradiol (E2), 17 $\alpha, 20 \beta$-dihydroxy-pregn-4-en-3-one $(D H P)$, testosterone $(T)$, and 11-ketotestosterone $(K T)$. Separation conditions are described in the text

cyclodextrin. Even though plasma samples were processed to facilitate stacking, each reconstituted plasma sample may contain compounds such as lipids and amphipathic molecules that hold potential to interfere with the suppressed electroosmotic flow as well as the secondary equilibria important to both stacking and separation. The method of sample preparation must minimize these effects, yet be compatible with plasma volumes as low as $5 \mu \mathrm{L}$.

Sample processing Steroid determinations were based on liquid-liquid extractions and on solid-phase extractions with commercially available cartridges. The purpose of the liquid extraction was to separate steroidal compounds from proteins, whereas the solid-phase extractions isolated steroids from amphipathic compounds, such as fatty acids, or molecules with different hydrophobicity, such as cholesterol. In a previous report, $0.1 \mathrm{~mL}$ volumes of plasma were processed with liquid-liquid extraction, and successive treatment with solidphase extraction based on cationic exchange and reversed phase $[28,29]$. This rigorous treatment did not remove interfering compounds that systematically reduced the recovery of estradiol $[28,29]$. In the present work, the sample was subjected to an extraction with ethyl acetate to separate proteins from hydrophobic steroidal compounds. The compounds captured in the organic phase were applied to a Hybrid SPE phospholipid cartridge, which was comprised of zirconia-coated silica designed to retain phospholipids and elute all other hydrophobic components. The eluted fraction was then applied to a reversed-phase cartridge to desalt the sample, which was then reconstituted in stacking buffer. Fractions eluted from each of the three processing steps were dried under vacuum at ambient temperature, for 15,90 , and $60 \mathrm{~min}$, respectively. The total time to process and evaporate the solvents was $\sim 3 \mathrm{~h}$. When sample processing was performed at ambient temperatures and required more than $4 \mathrm{~h}$, the recovery was decreased due to thermal and photodegradation. The current sample protocol was performed in parallel for up to six samples for a total processing time of $\sim 3 \mathrm{~h}$.

The recovery of steroidal compounds in plasma samples was achieved by combining plasma from two fish and then splitting the combined samples into two equal

Table 1 Detection limits with improved steroid stacking

\begin{tabular}{|c|c|c|c|c|c|c|c|}
\hline & & $\begin{array}{l}17 \alpha, 20 \beta \text {-Dihydroxy- } \\
\text { pregn-4-en-3-one }\end{array}$ & Testosterone & $\begin{array}{l}\text { 11-Keto } \\
\text { testosterone }\end{array}$ & Estrone & $17 \beta$-Estradiol & $\begin{array}{l}17 \alpha \text {-Ethinyl } \\
\text { estradiol }\end{array}$ \\
\hline \multicolumn{8}{|c|}{5 mM CAPS (this work) } \\
\hline \multirow[t]{2}{*}{$\mathrm{LOD}^{\mathrm{a}}$} & $\mathrm{nM}$ & $3.17 \pm 0.06$ & $2.8 \pm 0.1$ & $6.4 \pm 0.2$ & $2.69 \pm 0.09$ & $0.79 \pm 0.05$ & $0.96 \pm 0.04$ \\
\hline & $\mathrm{ng} / \mathrm{mL}$ & $1.05 \pm 0.02$ & $0.81 \pm 0.03$ & $1.94 \pm 0.06$ & $0.73 \pm 0.02$ & $0.21 \pm 0.01$ & $0.28 \pm 0.01$ \\
\hline \multicolumn{8}{|c|}{50 mM CAPS (refs $[28,29])$} \\
\hline \multirow[t]{2}{*}{ LOD } & $\mathrm{nM}$ & $11 \pm 3$ & $4 \pm 1$ & $14 \pm 3$ & $3.1 \pm 0.8$ & $2.9 \pm 0.06$ & $4.7 \pm 0.04$ \\
\hline & $\mathrm{ng} / \mathrm{mL}$ & $4 \pm 1$ & $1.0 \pm 0.3$ & $4.2 \pm 0.9$ & $0.8 \pm 0.2$ & $0.79 \pm 0.02$ & $1.4 \pm 0.02$ \\
\hline
\end{tabular}

Detection limits are obtained using a separation buffer comprised of $30 \mathrm{mM}$ sodium dodecyl sulfate and $13 \mathrm{mM}$ hydroxypropyl- $\beta$-CD in $200 \mathrm{mM}$ phosphate buffered at $\mathrm{pH}$ 2.5. Injection conditions, separation voltage, and capillary dimensions are outlined in the text

${ }^{a} S / N$ determined at a concentration of $100 \mathrm{nM}$ for $17 \alpha, 20 \beta$-dihydroxy-pregn-4-en-3-one $(n=10), 40 \mathrm{nM}$ for testosterone $(n=10), 100 \mathrm{nM}$ for 11 ketotestosterone $(n=10), 20 \mathrm{nM}$ for $17 \beta$-estradiol $(n=10), 100 \mathrm{nM}$ for estrone $(n=10)$, and $20 \mathrm{nM}$ for $17 \alpha$-ethinyl estradiol $(n=10)$ 
Table 2 Analytical figures of merit of steroid determination with stacking and separation

\begin{tabular}{|c|c|c|c|c|c|c|}
\hline & $\begin{array}{l}17 \alpha, 20 \beta \text {-Dihydroxy- } \\
\text { pregn-4-en-3-one }\end{array}$ & Testosterone & $\begin{array}{l}\text { 11-Keto } \\
\text { testosterone }\end{array}$ & Estrone & $17 \beta$-Estradiol & $\begin{array}{l}\text { Ethinyl } \\
\text { estradiol }\end{array}$ \\
\hline Linear range $^{\mathrm{a}}(\mathrm{nM})$ & $20-200$ & $10-200$ & $20-200$ & $20-200$ & $5-200$ & $5-200$ \\
\hline \multicolumn{7}{|c|}{ Reproducibility ${ }^{\mathrm{b}}$ within day $(n=10)$} \\
\hline Time (min) & $3.77 \pm 0.02$ & $4.17 \pm 0.04$ & $4.98 \pm 0.06$ & $4.57 \pm 0.06$ & $5.88 \pm 0.04$ & $5.50 \pm 0.05$ \\
\hline Area $\left(\times 10^{3}\right)$ & $0.53 \pm 0.05$ & $0.61 \pm 0.05$ & $0.22 \pm 0.01$ & $0.80 \pm 0.07$ & $2.1 \pm 0.1$ & $1.94 \pm 0.09$ \\
\hline \multicolumn{7}{|c|}{ Reproducibility $^{\mathrm{b}}$ day to day $(n=3)$} \\
\hline Time (min) & $3.4 \pm 0.3$ & $3.8 \pm 0.3$ & $4.4 \pm 0.4$ & $4.1 \pm 0.4$ & $5.3 \pm 0.6$ & $4.9 \pm 0.5$ \\
\hline Area $\left(\times 10^{3}\right)$ & $0.52 \pm 0.02$ & $0.60 \pm 0.01$ & $0.22 \pm 0.02$ & $0.81 \pm 0.06$ & $2.0 \pm 0.2$ & $2.0 \pm 0.3$ \\
\hline \multicolumn{7}{|l|}{ Recovery $^{c}$} \\
\hline Standard (\%) & $86 \pm 4$ & $104 \pm 4$ & $92 \pm 1$ & $90 \pm 9$ & $86 \pm 2$ & $100 \pm 2$ \\
\hline Zebrafish, heparin (\%) & $93 \pm 1$ & $83 \pm 6$ & $109 \pm 1$ & $108 \pm 5$ & $81 \pm 8$ & $109 \pm 8$ \\
\hline Zebrafish, water (\%) & $95 \pm 3$ & $85 \pm 1$ & $107 \pm 1$ & $101 \pm 3$ & $102 \pm 5$ & $98 \pm 4$ \\
\hline
\end{tabular}

${ }^{\text {a }}$ Curves at $254 \mathrm{~nm}$ were determined simultaneously for $17 \alpha, 20 \beta$-dihydroxy-pregn-4-en-3-one, testosterone, and 11 -ketotestosterone with $R^{2} \geq 0.995$. Curves at $200 \mathrm{~nm}$, with $R^{2} \geq 0.995$, were determined simultaneously for $17 \beta$-estradiol, estrone, and $17 \alpha$-ethinyl estradiol

${ }^{\mathrm{b}}$ Reproducibility determined using $50.0 \mathrm{nM}$ standards

${ }^{\mathrm{c}}$ Recovery for the standard is based on $50 \mathrm{nM}$ steroids, and fish plasma samples are based on spiking plasma with $50 \mathrm{nM}$ steroids with $2 \mu \mathrm{L}$ of added solution comprised of $6.5 \mathrm{mg}$ of low molecular weight heparin $/ \mathrm{mL}$ deionized water or with $2 \mu \mathrm{L}$ of added deionized water and were subject to the full preparation protocol outlined in the text

volumes. Endogenous steroids were measured in one fraction, while six steroidal compounds were spiked into the second fraction. Analysis of each fraction provided a means to account for the endogenous steroids in the plasma fraction spiked with steroid standards. The results, summarized in Table 2, demonstrated recoveries ranging from 81 to $109 \%$. The fish used for the recovery study were not reproductively active; thus, the endogenous steroids were below the quantification limit of this method (see ESM Fig. S1). The steroid separations obtained from the plasma samples migrated within $5 \%$ RSD of standard migration time. This shift in migration time that occurred with processed plasma samples was most likely due to the introduction of hydrophobic compounds that associate with the micelles and the cyclodextrins, altering the secondary equilibrium of the separation. Therefore, after the sample was separated and quantified, it was spiked with steroid standards (i.e., 17 $\alpha, 20 \beta$-dihydroxy-pregn-4-en-3one, testosterone, 11-ketotestosterone, estrone, 17 $\beta$-estradiol, and ethinyl estradiol) to verify the peak identification based on migration time.

For these determinations, the samples were quantified from a single separation to increase the sample throughput. In addition, the $30-\mu \mathrm{L}$ sample volumes are prone to evaporation, the steroids are subject to thermal and photodegradation, and the hydroxide ion is electrolytically generated in the cathodic reservoir during the 60-s injection. A single plasma sample was spiked with $1.5 \mathrm{pmol}$ each of $17 \alpha, 20 \beta$-dihydroxy-pregn-4-en-3-one, testosterone, 11-ketotestosterone, estrone, $17 \beta$-estradiol, and ethinyl estradiol. Following sample preparation and reconstitution in stacking buffer, the concentration of each steroid was $50 \mathrm{nM}$ when $100 \%$ recovery was achieved. A single sample was subjected to three analyses (see ESM Table S2). The relative error associated with each measurement when estimated from the calibration curve ranged from 2 to $7 \%$, whereas the relative error determined from the standard deviation associated with the replicate measurements ranged from 3 to $7 \%$. Although the error generated from replicate measurements was similar to that obtained from a single measurement with a calibration curve, estrone degraded into two peaks, which is attributed to chemical processes associated with injection. To avoid issues associated with repeated injections, the measurement error (see Tables 1, 2, 3, and 4) was estimated from the error associated with the calibration curve. Although evaporation effects will not be reduced, chemical processes can be minimized by using methods that are compatible with large-volume hydrodynamic injections if sweeping and stacking can be achieved for the steroid standards, detection limits of $5 \mathrm{ng} / \mathrm{mL}$ are sufficient [25], and high-throughput measurements are not required.

Exposure to $17 \beta$-estradiol The steroid $17 \beta$-estradiol is used as a positive control for estrogenic activity [5]. A total of 40 fish were exposed to solvent or to $17 \beta$ estradiol dissolved in solvent. A single set is composed of 10 fish (i.e., five male and five female) maintained in a tank set up as a flow-through system for chemical 
Table 3 Effect of $17 \beta$-estradiol exposure on circulating steroids (ng/mL plasma) of female zebrafish

\begin{tabular}{|c|c|c|c|c|c|}
\hline Treatment & $\begin{array}{l}17 \alpha, 20 \beta \text {-Dihydroxy- } \\
\text { pregn-4-en-3-one }\end{array}$ & Testosterone & $\begin{array}{l}\text { 11-Keto } \\
\text { testosterone }\end{array}$ & Estrone & $17 \beta$-Estradiol \\
\hline \multicolumn{6}{|c|}{ Set 1: 16.9 weeks of age for exposure experiments } \\
\hline Ethanol 1 & ND & ND & ND & ND & ND \\
\hline Ethanol 2 & ND & ND & ND & ND & ND \\
\hline Ethanol 3 & ND & ND & ND & ND & $188 \pm 1$ \\
\hline Ethanol 4 & ND & $37 \pm 8$ & ND & ND & ND \\
\hline Ethanol 5 & $115 \pm 3$ & ND & ND & ND & ND \\
\hline Results if pooled & 23 & 7 & & & 38 \\
\hline $100 \mathrm{ng} / \mathrm{L}$ estradiol 6 & ND & $32 \pm 6$ & ND & ND & ND \\
\hline $100 \mathrm{ng} / \mathrm{L}$ estradiol 7 & ND & $33 \pm 6$ & ND & ND & ND \\
\hline $100 \mathrm{ng} / \mathrm{L}$ estradiol 8 & ND & ND & ND & $214 \pm 6$ & ND \\
\hline $100 \mathrm{ng} / \mathrm{L}$ estradiol 9 & ND & $34 \pm 8$ & ND & $118 \pm 4$ & ND \\
\hline $100 \mathrm{ng} / \mathrm{L}$ estradiol 10 & ND & ND & ND & $223 \pm 1$ & ND \\
\hline Results if pooled & & 20 & & 111 & \\
\hline \multicolumn{6}{|c|}{ Set 2: 33.3 weeks of age for exposure experiments } \\
\hline Ethanol 11 & $112 \pm 3$ & ND & $110 \pm 2$ & ND & ND \\
\hline Ethanol 12 & ND & ND & $88 \pm 2$ & ND & ND \\
\hline Ethanol 13 & $74 \pm 3$ & ND & $77 \pm 2$ & ND & ND \\
\hline Ethanol 14 & $82 \pm 4$ & ND & ND & ND & ND \\
\hline Ethanol 15 & ND & ND & ND & ND & ND \\
\hline Results if pooled & 54 & & 55 & & \\
\hline $100 \mathrm{ng} / \mathrm{L}$ estradiol 16 & ND & $26 \pm 6$ & $46 \pm 6$ & ND & $39 \pm 4$ \\
\hline $100 \mathrm{ng} / \mathrm{L}$ estradiol 17 & ND & $41 \pm 5$ & $34 \pm 6$ & $53 \pm 2$ & ND \\
\hline $100 \mathrm{ng} / \mathrm{L}$ estradiol 18 & ND & ND & $53 \pm 7$ & $127 \pm 2$ & ND \\
\hline $100 \mathrm{ng} / \mathrm{L}$ estradiol 19 & ND & $23 \pm 7$ & $70 \pm 7$ & $115 \pm 2$ & ND \\
\hline $100 \mathrm{ng} / \mathrm{L}$ estradiol 20 & ND & $27 \pm 7$ & ND & $120 \pm 2$ & ND \\
\hline Results if pooled & & 23 & 41 & 83 & 8 \\
\hline
\end{tabular}

exposure as mandated by guidelines reported by the Organisation for Economic Co-operation and Development [5]. Two sets were exposed to ethanol. Two sets were exposed to $17 \beta$-estradiol dissolved in ethanol. From these four exposure tanks, a total of 20 individual female fish (i.e., five females/tank) were studied by monitoring circulating steroids with the capillary electrophoresis method described in this paper. Blood collected from each fish in set 2 was spiked with 1.5 pmol of the synthetic steroid ethinyl estradiol prior to processing to confirm the compatibility of the method with an internal standard. Egg production was monitored during the exposure experiments because impaired reproduction is a critical indicator of endocrine disruption. The results summarized in ESM Fig. S2 demonstrate a change in egg production and hatching rate in the presence of estradiol, but the information provides little insight into the underlying mechanism of endocrine disruption.
Table 4 Effect of acetone exposure on circulating steroids (ng/mL plasma) of female zebrafish

\begin{tabular}{llllll}
\hline Treatment & $\begin{array}{l}17 \alpha, 20 \beta \text {-Dihydroxy- } \\
\text { pregn-4-en-3-one }\end{array}$ & Testosterone & $\begin{array}{l}\text { 11-Keto } \\
\text { testosterone }\end{array}$ & Estrone & 17ß-Estradiol \\
\hline Acetone 21 & $70 \pm 2$ & ND & $40 \pm 2$ & ND & ND \\
Acetone 22 & ND & ND & ND & $63 \pm 6$ & $39 \pm 1$ \\
Acetone 23 & $105 \pm 2$ & ND & $108 \pm 2$ & $98 \pm 7$ & $128 \pm 1$ \\
Acetone 24 & ND & ND & ND & $112 \pm 7$ & ND \\
Acetone 25 & ND & ND & ND & $201 \pm 6$ & ND \\
Results if pooled & 35 & & 30 & 95 & 33 \\
\hline
\end{tabular}


The data summarized in Table 3 reveal the changes in total circulating steroid hormone that occurred in female fish exposed to $17 \beta$-estradiol. An advantage to monitoring steroids from individual fish is that information about hormonal balance is lost when samples are combined and analyzed. To demonstrate this, the data in Table 3 indicates the results obtained if the data were pooled instead of measured individually. These analyses of multiple steroids in single fish established for the first time changes in estrone in small model fish associated with estrogenic activity. Literature studies of circulating steroids in zebrafish are limited to classical steroids: $17 \beta$-estradiol, testosterone, and 11-ketotestosterone; however, no changes were detected in these steroids using capillary electrophoresis. With the use of a method to identify multiple steroids simultaneously, altered steroid levels are rapidly identified in individuals.

Relative to control fish, in which no estrone was detected, three fish in set 1 , which was composed of fish that were 16.9 weeks old, had circulating estrone ranging from 118 to $233 \mathrm{ng} / \mathrm{mL}$ (see Fig. 2 and Table 3). Set 2
Set 1

(a) Solvent Control

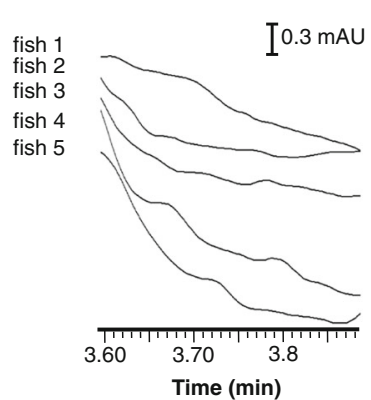

Set 1
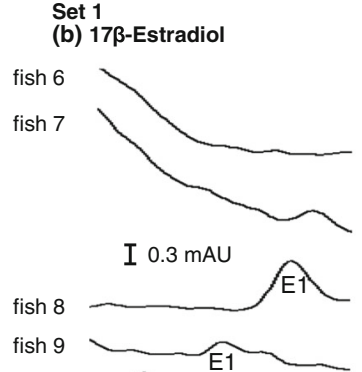
fish 10

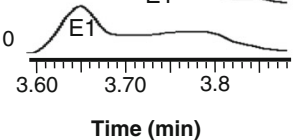

Set 2

(c) Solvent Control

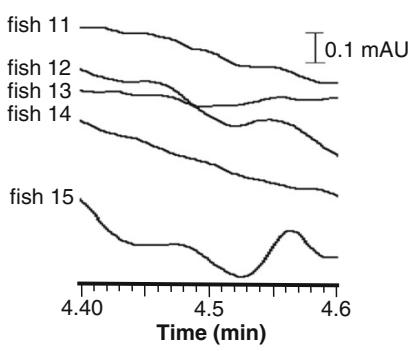

(d) $17 \beta$-Estradiol

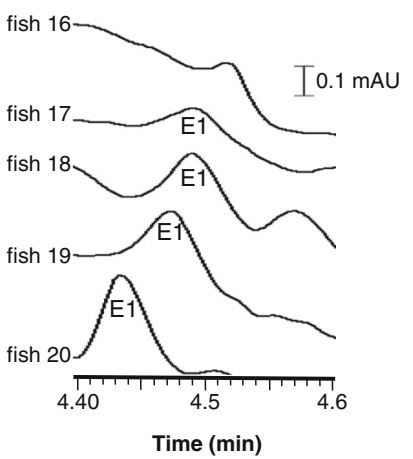

Fig. 2 Stacked electropherograms from individual female zebrafish. Set 1 fish are 16.9 weeks of age at the time of exposure to (a) ethanol solvent only or (b) $17 \beta$ estradiol dissolved in ethanol solvent. Set 2 fish are 33.3 weeks of age at the time of exposure to (c) ethanol solvent only or (d) $17 \beta$ estradiol dissolved in ethanol solvent. Blood collected from fish analyzed in set 2 was spiked with ethinyl estradiol prior to sample processing to confirm the use of internal standards. Estrone is labeled as $E 1$. Separation conditions are described in the text. Estrone is confirmed by spiking and then separating each sample after it was quantified was composed of fish that were 33 weeks old, and following exposure to $17 \beta$-estradiol, four fish had circulating estrone ranging from 53 to $127 \mathrm{ng} / \mathrm{mL}$ (see Fig. 2 and Table 3). Thus, despite a difference in age, there is an increase in estrone levels in a majority of female fish following exposure to $17 \beta$-estradiol. Circulating estrone has never been detected in zebrafish but has been detected in larger fish, including flounder (Platichthys flesus) [6], yellow perch (Perca fluviatilis) [30], and catfish (Clarias batrachus) [31]. Based on another exposure study reported in the literature, estrone is implicated in early stages of vitellogenesis [34]. Estrone interacts with estrogen receptors and is more rapidly metabolized than synthetic steroids. Tools such as the Kyoto Encyclopedia of Genes and Genomes (KEGG) database demonstrate the interrelated pathways of steroid biosynthesis for zebrafish [35]. The scheme in Fig. 3, adapted from the KEGG database map, indicates that estrone is an endpoint of multiple synthesis pathways including $17 \beta$-estradiol via $17 \beta$-hydroxysteroid dehydrogenase.

Effects of acetone on circulating estrone In addition to ethanol [36], acetone [37] has also been reported as a solvent used to solubilize $17 \beta$-estradiol for exposure studies with zebrafish. The effect of acetone was assessed with reproductively active female zebrafish following a 7-day chemical exposure with a flow-through system. One set of 10 fish was exposed to acetone, and five individual female fish were studied using $\mathrm{pH}$-mediated stacking and capillary electrophoresis. Estrone was detected in four female fish exposed to acetone with a circulating estrone ranging from 63 to $201 \mathrm{ng} / \mathrm{mL}$ (see Table 4). Different organic solvents may be used as the delivery vehicle for sparingly soluble compounds, although preliminary studies must be performed to verify that the presence of the delivery solvent has little or no effect on the endocrine system [38]. The generation of circulating estrone following acetone exposure warrants caution when using this solvent.

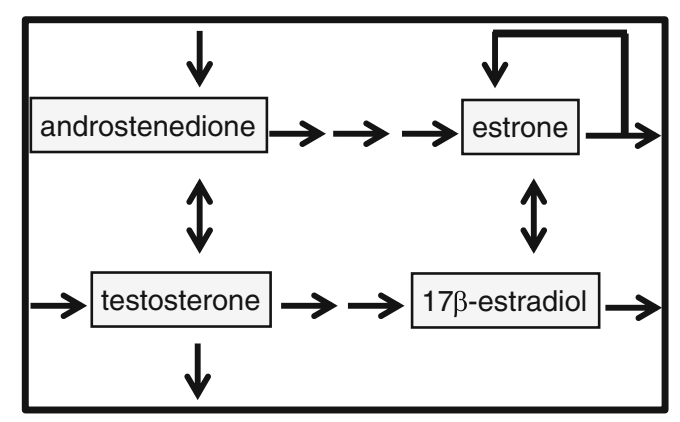

Fig. 3 Interrelated pathways of testosterone, $17 \beta$-estradiol, and estrone biosynthesis 


\section{Conclusions and future directions}

The reported capillary electrophoresis method is amenable to the limited sample volume generated by individual zebrafish and provides a rapid means to measure multiple steroids in the large number of samples required for toxicity testing. The analysis of circulating steroids provided more insight about mechanisms of endocrine disruption relative to the information derived by monitoring physiological endpoints such as egg production. Estrone has not been previously detected in zebrafish due to the lack of an available validated antibody assay and because the blood volume is too low for analysis by mass spectrometry methods. An example of the advantage of this approach is supported by the measurement of circulating estrone. The method is currently being applied to study the effects of other endocrine-disrupting chemicals.

Acknowledgments Research in this report was supported by the National Institute of Environmental Health Sciences under award number 5R21ES023575. MCGE acknowledges support from the National Science Foundation (IGERT Continuing grant: 1144676).

Open Access This article is distributed under the terms of the Creative Commons Attribution 4.0 International License (http:// creativecommons.org/licenses/by/4.0/), which permits unrestricted use, distribution, and reproduction in any medium, provided you give appropriate credit to the original author(s) and the source, provide a link to the Creative Commons license, and indicate if changes were made.

\section{References}

1. Diamanti-Kandarakis E, Bourguignon J-P, Giudice LC, Hauser R, Prins GS, Soto AM, Zoeller RT, Gore AC (2009) Endocrinedisrupting chemicals: an endocrine society scientific statement. Endocr Rev 30(4):293-342

2. Hill AJ, Teraoka H, Heideman W, Peterson RE (2005) Zebrafish as a model vertebrate for investigating chemical toxicity. Toxicol Sci 86(1):6-19

3. Scholz S, Mayer I (2008) Molecular biomarkers of endocrine disruption in small model fish. Mol Cell Endocrinol 293(1-2):57-70

4. Kime DE (1993) 'Classical' and 'non-classical' reproductive steroids in fish. Rev Fish Biol Fish 3:160-180

5. OECD (2012) Organisation for Economic Co-operation and Development. Test no. 229: fish short term reproduction assay. In: OECD guidelines for the testing of chemicals, section 2: effects on biotic systems. OECD Publishing

6. Budzinski H, Devier MH, Labadie P, Togola A (2006) Analysis of hormonal steroids in fish plasma and bile by coupling solid-phase extraction to GC/MS. Anal Bioanal Chem 386:1429-1439

7. Krone N, Hughes BA, Lavery GG, Stewart PM, Arlt W, Shackleton CHL (2010) Gas chromatography/mass spectrometry (GC/MS) remains a pre-eminent discovery tool in clinical steroid investigations even in the era of fast liquid chromatography tandem mass spectrometry (LC/MS/MS). J Steroid Biochem Mol Biol 121(3-5):496504

8. Abdel-Khalik J, Björklund E, Hansen M (2013) Simultaneous determination of endogenous steroid hormones in human and animal plasma and serum by liquid or gas chromatography coupled to tandem mass spectrometry. J Chromatogr B 928:58-77

9. Stanczyk FZ, Clarke NJ (2010) Advantages and challenges of mass spectrometry assays for steroid hormones. J Steroid Biochem Mol Biol 121(3-5):491-495

10. Liu C, Deng J, Yu L, Ramesh M, Zhou B (2010) Endocrine disruption and reproductive impairment in zebrafish by exposure to $8: 2$ fluorotelomer alcohol. Aquat Toxicol 96(1):70-76

11. Liu C, Yu L, Deng J, Lam PKS, Wu RSS, Zhou B (2009) Waterborne exposure to fluorotelomer alcohol 6:2 FTOH alters plasma sex hormone and gene transcription in the hypothalamic-pituitary-gonadal (HPG) axis of zebrafish. Aquat Toxicol 93(2-3):131-137

12. Deng J, Liu C, Yu L, Zhou B (2010) Chronic exposure to environmental levels of tribromophenol impairs zebrafish reproduction. Toxicol Appl Pharmacol 243(1):87-95

13. Chang J, Liu S, Zhou S, Wang M, Zhu G (2013) Effects of butachlor on reproduction and hormone levels in adult zebrafish (Danio rerio). Exp Toxicol Pathol 65(1-2):205-209

14. Liu X, Ji K, Choi K (2012) Endocrine disruption potentials of organophosphate flame retardants and related mechanisms in H295R and MVLN cell lines and in zebrafish. Aquat Toxicol 114-115:173-181

15. Brown AR, Bickley LK, Le Page G, Hosken DJ, Paull GC, Hamilton PB, Owen SF, Robinson J, Sharpe AD, Tyler CR (2011) Are toxicological responses in laboratory (inbred) zebrafish representative of those in outbred (wild) populations? - a case study with an endocrine disrupting chemical. Environ Sci Technol 45(9):4166-4172

16. Velasco-Santamaría YM, Korsgaard B, Madsen SS, Bjerregaard P (2011) Bezafibrate, a lipid-lowering pharmaceutical, as a potential endocrine disruptor in male zebrafish (Danio rerio). Aquat Toxicol 105(1-2):107-118

17. Coe TS, Hamilton PB, Hodgson D, Paull GC, Stevens JR, Sumner K, Tyler CR (2008) An environmental estrogen alters reproductive hierarchies, disrupting sexual selection in group-spawning fish. Environ Sci Technol 42(13):5020-5025

18. Christianson-Heiska I, Smeds P, Granholm N, Bergelin E, Isomaa B (2007) Endocrine modulating actions of a phytosterol mixture and its oxidation products in zebrafish (Danio rerio). Comp Biochem Physiol C 145(4):518-527

19. Hoffmann JL, Thomason RG, Lee DM, Brill JL, Price BB, Carr GJ, Versteeg DJ (2008) Hepatic gene expression profiling using GeneChips in zebrafish exposed to 17a-methyldihydrotestosterone. Aquat Toxicol 87(2):69-80

20. Christianson-Heiska I-L, Haavisto T, Paranko J, Bergelin E, Isomaa B (2008) Effects of the wood extractives dehydroabietic acid and betulinol on reproductive physiology of zebrafish (Danio rerio) - a two-generation study. Aquat Toxicol 86(3):388-396

21. Munro NJ, Palmer J, Stalcup AM, Landers JP (1999) Charged cyclodextrin-mediated sample stacking in micellar capillary electrophoresis. A simple method for enhancing the detection sensitivity of hydrophobic compounds. J Chromatogr B 731:369-381

22. Šlampová A, Malá Z, Panti̊čková P, Gebauer P, Boček P (2013) Contemporary sample stacking in analytical electrophoresis. Electrophoresis 34(1):3-18

23. Breadmore MC, Sänger-van de Griend CE, Majors RE (2014) Incapillary sample concentration in CE. LC-GC North America 32(3):174-186

24. Wang C-C, Cheng S-F, Cheng H-L, Chen Y-L (2013) Analysis of anabolic androgenic steroids in urine by full-capillary sample injection combined with a sweeping CE stacking method. Anal Bioanal Chem 405(6):1969-1976

25. Wang C-C, Chen J-L, Chen Y-L, Cheng H-L, Wu S-M (2012) A novel stacking method of repetitive large volume sample injection and sweeping MEKC for determination of androgenic steroids in urine. Anal Chim Acta 744:99-104 
26. Britz-McKibbin P, Ichihashi T, Tsubota K, Chen DDY, Terabe S (2003) Complementary on-line preconcentration strategies for steroids by capillary electrophoresis. J Chromatogr A 1013(1-2):65-76

27. Bykova L (2009) Steroid analysis by $\mathrm{pH}$-mediated stacking MEKC. Ph.D. Dissertation, West Virginia University, Morgantown

28. Bykova L, Archer-Hartmann SA, Holland LA, Iwanowicz LR, Blazer VS (2010) Steroid determination in fish plasma using capillary electrophoresis. Environ Toxicol Chem 29(9): 1950-1956

29. Bykova L, Holland LA (2008) Stacking enhanced determination of steroids by CE. Electrophoresis 29(18):3794-3800

30. Noaksson E, Gustavsson B, Linderoth M, Zebühr Y, Broman D, Balk L (2004) Gonad development and plasma steroid profiles by HRGC/HRMS during one reproductive cycle in reference and leachate-exposed female perch (Perca fluviatilis). Toxicol Appl Pharmacol 195(2):247-261

31. Singh S, Singh TP (1987) Seasonal profiles of sex steroids in blood plasma and ovarian tissue of Clarias batrachus. Gen Comp Endocrinol 65(2):216-224

32. Burgi DS, Chien RL (1991) Optimization in sample stacking for high-performance capillary electrophoresis. Anal Chem 63(18): 2042-2047
33. Bard AJ, Faulkner LR (1980) Electrochemical methods. John Wiley and Sons, New York

34. Van den Belt K, Berckmans P, Vangenechten C, Verheyen R, Witters H (2004) Comparative study on the in vitro/in vivo estrogenic potencies of $17 \beta$-estradiol, estrone, $17 \alpha$-ethynylestradiol and nonylphenol. Aquat Toxicol 66(2):183-195

35. Kanehisa M, Goto S, Sato Y, Kawashima M, Furumichi M, Tanabe M (2014) Data, information, knowledge and principle: back to metabolism in KEGG. Nucleic Acids Res 42(D1):D199-D205

36. van der Ven LTM, van den Brandhof E-J, Vos JH, Wester PW (2007) Effects of the estrogen agonist $17 \beta$-estradiol and antagonist tamoxifen in a partial life-cycle assay with zebrafish (Danio rerio). Environ Toxicol Chem 26(1):92-99

37. Brion F, Tyler CR, Palazzi X, Laillet B, Porcher JM, Garric J, Flammarion $P$ (2004) Impacts of $17 \beta$-estradiol, including environmentally relevant concentrations, on reproduction after exposure during embryo-larval-, juvenile- and adult-life stages in zebrafish (Danio rerio). Aquat Toxicol 68(3):193-217

38. Hutchinson TH, Shillabeer N, Winter MJ, Pickford DB (2006) Acute and chronic effects of carrier solvents in aquatic organisms: a critical review. Aquat Toxicol 76(1):69-92 